\title{
REVISTA CIENTÍFICA
}

\section{A utilização do agregado fuligem como uma alternativa sustentável para mistura do concreto}

The use of the aggregate fulfills as a sustainable alternative for concrete mixture

La utilización del agregado fuligen como una alternativa sostenible para la mezcla del concreto

\author{
Gean Pereira da Silva Junior \\ Aluno, UNIP, Brasil \\ Gean.junior1995@gmail.com \\ João Vitor Meneguetti Berti \\ Aluno, UNESP, Brasil \\ jvmb97@gmail.com \\ Jose Antonio Armani Paschoal \\ Professor Doutor, UNIP, Brasil. \\ Armani@armaniconsult.com.br
}




\section{REVISTA CIENTÍFICA}

\section{INTRODUÇÃO}

O concreto, um dos principais componentes da engenharia empregados pelo homem, é também um dos maiores causadores da degradação ambiental. Desde a antiguidade já haviam compostos formado por água, agregados e aglomerantes servindo de matéria prima para a construção de diversas estruturas que persistem ao longo dos séculos às ações intempéricas diversas e perduram até os dias atuais. De acordo com os estudos realizados pelo Sindicato Nacional da Indústria do Cimento - SNIC (2010) foram indicados uma produção de cerca de 2,5 bilhões de toneladas por ano de cimento Portland no mundo, o Brasil é o décimo maior produtor de cimento do mundo e, o primeiro da América Latina, produzindo cerca de 59,80 milhões de toneladas de cimento só no ano de 2009.

Há uma grande preocupação pela busca de alternativas sustentáveis em relação aos produtos que são descartados na natureza sem nenhum tipo de tratamento, o que resulta em degradação do meio ambiente. Os produtos que são descartados na natureza sem nenhum tipo de tratamento são os concretos e massas utilizadas para a construção civil. Diversas usinas descartam resíduos derivados da queima do bagaço da cana - de - açúcar, o que consequentemente resulta num aumento do número de descarte. Tendo como base esse produto derivado de resíduos da cana, pode ser comprovado que é possível a utilização de materiais descartáveis, reaproveitando-os e utilizando-os na produção de um concreto mais resistente, firme, mais flexível, e, inclusive, esse concreto não trará danos para o meio ambiente, assim como o concreto que não é misturado com material descartável traz.

Como já dito anteriormente, o concreto é um dos maiores causadores da degradação ambiental, e devido a esse fator alarmante, é necessário que haja uma forma mais sustentável que possa desempenhar a mesma função do concreto e que não prejudique o meio ambiente (SOUTO, 2010). A alternativa mais viável que pode ser utilizada é o agregado, por razões econômicas e também pela sua importância para o meio ambiente. Estudos comprovam que $75 \%$ do volume do concreto é ocupado pelos agregados, o que, de certa forma, gera uma economia no valor gasto em material, além de que o concreto terá maior solidez e maior durabilidade do que só a mistura de cimento com água (LEVY, 2001). Logo, as propriedades físicas, térmicas e químicas do agregado têm um bom desempenho no quesito durabilidade do concreto, e também, um custo de menor valor e há uma grande facilidade em misturá-los ao concreto.

Existem críticas em relação ao uso de agregados naturais para a produção de concreto, portanto, com o uso da reciclagem de materiais, outra fonte de matéria-prima passa a ser utilizada e proporciona a redução da disposição e no volume final do resíduo. 


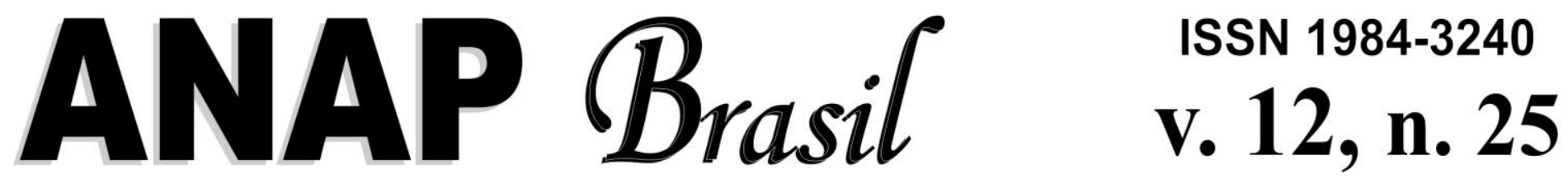

\section{REVISTA CIENTÍFICA}

Apesar das críticas com o uso de agregados, há grandes chances de que a mistura de concreto com o agregado produza um resultado final de grande qualidade, pois, pode ser utilizado o concreto convencional (CC) como um substituto aos agregados naturais por agregados advindos da cana - de - açúcar. Sendo assim, para que este concreto seja utilizado em grande escala, é necessário que ele seja utilizado na produção de elementos construtivos e que esses elementos correspondam à maior parte do consumo deste material.

A utilização da fuligem tem como base fundamental aumentar a resistência que este concreto atinge ao curar, evitando assim a necessidade de se utilizar um volume muito maior de materiais como areia e cimento. Logo, há uma economia de material, o que resulta na economia do custo total da obra, fator extremamente importante, já que uma das maiores funções de um engenheiro é de minimizar ao máximo os custos de um trabalho, e, conseguir realizar este trabalho com qualidade.

Dessa forma, pode-se entender o porquê da utilização do agregado fuligem é de extrema importância, tanto para o meio ambiente, quanto para o custo benefício total de uma grande construção. Além de sua produção ser bem menos prejudicial ao meio ambiente, o seu custo será reduzido já que é um tipo de material reciclado que tem um bom desempenho quando misturado ao cimento em condições favoráveis.

\section{OBETIVOS}

O objetivo do trabalho é gerar a conciliação do agregado fuligem de cana-de-açúcar atingir os diagramas de dosagem de concreto variando os agregados naturais junto com a fuligem, considerando-se a possibilidade de utilização do mesmo gerado, pela usina de cana-de-açúcar, como substituto parcial do cimento na produção do concreto. Realizando assim a comparação das características do concreto convencional (CC) com as características do concreto com adição de agregado fuligem (CF) de cana-de-açúcar.

\section{MATERIAS E MÉTODOS}

\subsection{MATERIAIS}

\subsubsection{Agregados miúdos}

Os agregados miúdos utilizado na pesquisa foram:

- Areia Grossa Natural tem a origem do Porto de Areia Irmãos Brambilla, de Pereira Barreto $-\mathrm{SP}$.

- Fuligem, gerada a partir da combustão do bagaço da cana-de-açúcar, proveniente da Usina Santa Adélia, localizada na cidade de Pereira Barreto - SP. 


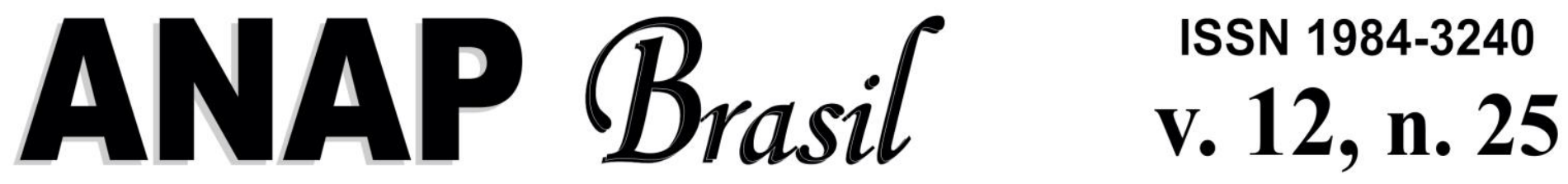

\section{REVISTA CIENTÍFICA}

\subsubsection{Ensaio de Consistência}

Logo após a mistura, realizou-se o ensaio de abatimento de tronco de cone, também conhecido como "slump test", seguindo a norma NBR NM 67:1998, com o objetivo de verificar se a consistência do concreto estava de acordo com a desejada para o propósito que o mesmo seria utilizado.

\subsubsection{Adensamento Manual.}

Foi introduzido o concreto no corpo de prova em 2 camadas, a primeira camada foi adicionada aproximadamente na metade, fazendo 12 golpes com a haste, evitando-se golpear a base do molde. Os golpes foram distribuídos uniformemente em toda a seção transversal do mesmo, em seguida foi adicionada a segunda camada de concreto completando todo o volume do molde, repetindo a quantidade de golpes com penetração de $20 \mathrm{~mm}$ na camada anterior. Por fim foi feito o rasamento da superfície com uma colher de pedreiro. Seguindo a norma NBR 5738:2015.

\subsubsection{Capeamento}

O capeamento é realizado para fazer a regularização dos corpos de prova, após analisar a trabalhabilidade para cada traço, a fim de efetuar o ensaio de compressão axial.

Para isso, foi utilizado gesso. Todos os corpos de prova foram capeados com o mesmo, respeitando o limite máximo de espessura da camada de $3 \mathrm{~mm}$ em cada base. Para que ambas as superfícies fiquem lisas e planas após o endurecimento.

\subsubsection{Ensaio de resistência à compressão axial}

Posteriormente o período de cura dos corpos de prova, foram realizados os ensaios de resistência a compressão axial simples. As idades de ensaios dos corpos de prova foram de 7 , 28 e 90 dias para a substituição em porcentagem de $15 \%$ com adição de $50 \mathrm{ml}$ de aditivo (superplastificante), em relação ao aglomerante utilizado, os mesmos foram posicionados no centro do prato inferior para que seu eixo seja o mesmo que o da prensa, deste modo as forças resultantes passam pelo centro do corpo de prova, utilizando uma prensa universal sob velocidade de $0,45 \pm 0,15 \mathrm{MPa} / \mathrm{s}$.

Os dados de resistência à compressão foram calculados conforme a NBR 5738, 2015. 


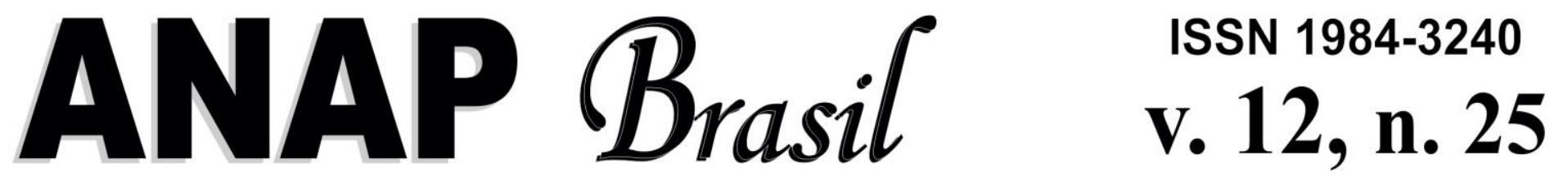

\section{REVISTA CIENTÍFICA 2019}

Porém o concreto com uso de uso de aditivo (superplastificante), necessita-se de uma quantidade menor de água, pois a mesma apresentou uma melhor aglutinação comparada ao concreto convencional (CC).

\subsection{Resultados de resistência à compressão}

Os resultados de resistência à compressão do concreto convencional (CC), e do concreto com fuligem e aditivo (CFP), com 7, 28 e 91 dias, estão representados na tabela 1.

Tabela 1 - Resultados de resistência à compressão para a substituição estudada

\begin{tabular}{|c|c|c|c|c|c|}
\hline \multicolumn{6}{|c|}{ Ensaio de compressão } \\
\hline Idade & Concreto & Carga (kgf) & Tensão (MPa) & Tensão Média (MPa) & Desvio Padrão \\
\hline \multirow{6}{*}{7 Dias } & \multirow{3}{*}{$\begin{array}{c}\text { Concreto } \\
\text { convencional } \\
\text { (CC) }\end{array}$} & 11870 & 14,82 & \multirow{3}{*}{15,34} & \multirow{3}{*}{ 2,186869909 } \\
\hline & & 10780 & 13,46 & & \\
\hline & & 14210 & 17,74 & & \\
\hline & \multirow{3}{*}{$\begin{array}{c}\text { Fuligem com } \\
\text { superplastifica } \\
\text { nte (CFP) }\end{array}$} & 10370 & 12,94 & \multirow{3}{*}{13,78} & \multirow{3}{*}{0,88228869} \\
\hline & & 11780 & 14,70 & & \\
\hline & & 10980 & 13,71 & & \\
\hline \multirow{6}{*}{28 Dias } & \multirow{3}{*}{$\begin{array}{l}\text { Concreto } \\
\text { convencional } \\
\text { (CC) }\end{array}$} & 15670 & 19,57 & \multirow{3}{*}{18,57} & \multirow{3}{*}{1,798786628} \\
\hline & & 15730 & 19,64 & & \\
\hline & & 13210 & 16,49 & & \\
\hline & \multirow{3}{*}{$\begin{array}{c}\text { Fuligem com } \\
\text { superplastifica } \\
\text { nte (CFP) }\end{array}$} & 15370 & 19,19 & \multirow{3}{*}{18,96} & \multirow{3}{*}{0,32929217} \\
\hline & & 14880 & 18,58 & & \\
\hline & & 15300 & 19,10 & & \\
\hline \multirow{6}{*}{91 Dias } & \multirow{3}{*}{$\begin{array}{c}\text { Concreto } \\
\text { convencional } \\
\text { (CC) }\end{array}$} & 17310 & 21,61 & \multirow{3}{*}{21,37} & \multirow{3}{*}{3,675880847} \\
\hline & & 19960 & 24,92 & & \\
\hline & & 14087 & 17,58 & & \\
\hline & \multirow{3}{*}{$\begin{array}{c}\text { Fuligem com } \\
\text { superplastifica } \\
\text { nte (CFP) }\end{array}$} & 22449 & 28,03 & \multirow{3}{*}{24,11} & \multirow{3}{*}{ 4,986404851 } \\
\hline & & 14820 & 18,50 & & \\
\hline & & 20670 & 25,81 & & \\
\hline
\end{tabular}

Fonte: PRÓPRIO AUTOR, 2016.

Pode-se observar que o concreto com fuligem e aditivo (CFP) com idade de 7 dias, suas devidas resistência ficaram abaixo do concreto convencional. Logo, para a idade de 28 dias, a sua resistência ultrapassou a resistência do concreto convencional. Com 90 dias, o concreto com fuligem e aditivo apresentou uma resistência significativa comparado com a resistência do concreto convencional. 
